\title{
Research on the Use of Mobile Devices and Headphones on Pedestrian Crossings-Pilot Case Study from Slovakia
}

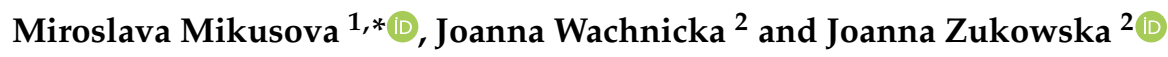 \\ 1 Department of Road and Urban Transport, Faculty of Economics of Transport and Communications, \\ University of Zilina, Univerzitná 8215/1, 01026 Zilina, Slovakia \\ 2 Faculty of Civil and Environmental Engineering, Gdansk University of Technology, \\ 11/12 Gabriela Narutowicza Street, 80-233 Gdansk, Poland; joanna.wachnicka@pg.edu.pl (J.W.); \\ joanna.zukowska@pg.edu.pl (J.Z.) \\ * Correspondence: mikusova@fpedas.uniza.sk
}

Citation: Mikusova, M.;

Wachnicka, J.; Zukowska, J. Research on the Use of Mobile Devices and Headphones on Pedestrian Crossings-Pilot Case Study from Slovakia. Safety 2021, 7, 17. https:// doi.org/10.3390/safety7010017

Academic Editors: Francisco Alonso, Sergio A. Useche and Tom Brijs

Received: 9 November 2020

Accepted: 19 February 2021

Published: 2 March 2021

Publisher's Note: MDPI stays neutral with regard to jurisdictional claims in published maps and institutional affiliations.

Copyright: (c) 2021 by the authors. Licensee MDPI, Basel, Switzerland. This article is an open access article distributed under the terms and conditions of the Creative Commons Attribution (CC BY) license (https:// creativecommons.org/licenses/by/ $4.0 /)$.

\begin{abstract}
The topic of the use of mobile devices and headphones on pedestrian crossings is much less explored in comparison to the use of the mobile phone while driving. Recent years have seen many discussions on this issue, especially in foreign countries. The Slovak Republic, however, has not been giving it enough attention (and it is not mentioned in the National Road Safety Plan for the Slovak Republic from 2011 to 2020). This paper aims to draw attention to this issue. It presents basic outputs of a pilot study on pedestrian safety, with a focus on the use of mobile devices and headphones at selected non-signalized pedestrian crossings in three Slovak cities. Overall, $9 \%$ of pedestrians used headphones or mobile devices at observed pedestrian crossings ( $4 \%$ of them used headphones, $1 \%$ used headphones and at same time used their mobile phone, $2 \%$ made phone calls and $2 \%$ used their mobile phones). While these numbers can be considered relatively low, the study proved that during weekdays every 2 min someone was using the crossing without fully focusing on crossing the road safely. Another main finding was that although the safety risk at pedestrian crossings is increased by factors such as rush hour traffic or reduced visibility, pedestrian behavior related to the use of mobile phones and headphones does not change. A safety assessment was also carried out at the crossings. The results show that pedestrian behavior is not affected by the level of safety of the crossing (e.g., visibility of the crossing for drivers). The results of the presented analysis suggest that action is needed to change that. Due to the lack of information about accidents involving pedestrians using mobile phones and headsets when crossing the road, no relevant statistical data could be analyzed. The dataset collected can be used as a basis for further investigation or comparisons with other countries of the relevant indicators. In future work, we would like to include a pedestriandriver interaction factor focusing on driver speed behavior in relation to pedestrians (who are on or are about to step onto a pedestrian crossing) and identify critical situations caused by improper behavior of drivers and/or pedestrians. This will help to understand speed adjustment problems related to pedestrian crossings.
\end{abstract}

Keywords: headphones; mobile phones; road safety; vulnerable road users; pedestrian crossings

\section{Introduction}

Pedestrians, along with cyclists and motor cyclists, are vulnerable road users. These are road users who are often seriously injured or killed in road accidents because they are unprotected against the speed and mass and they do not have effective safety features compared to other road users. The vulnerability of particular groups can be expressed through a vulnerability index. For example, in the case of a collision with a vehicle, we can calculate the pedestrian-vehicle crash vulnerability index by dividing the number of serious injuries of car passengers by the number of seriously injured pedestrians. The higher the resulting value of the vulnerability index, the greater the vulnerability of a given group of road users [1]. 
Pedestrians represent an important group of road users and one of the most vulnerable groups. According to the most recent statistics, vulnerable road-users account for $70 \%$ of road deaths in urban areas. Pedestrians represent $21 \%$ of total fatalities. Within urban areas, pedestrians account for the largest share of victims: inside urban areas, almost $40 \%$ of the fatalities are pedestrians [2]. They account for a large proportion of road traffic casualties and their vulnerability index is also the highest.

Pedestrian crossings are considered by the general public as a safe place for pedestrians. Unfortunately, according to the statistics, most pedestrian accidents happen on pedestrian crossings. For this reason, a growing attention is paid to the issue of pedestrian behavior not only at the level of transportation research but also at the level of sociological and psychological research.

It is well known that the development of today's society has brought a large increase in the number of mobile phones and headphones users. These devices are becoming an integral part of our lives, regardless of gender and age. This fact is confirmed by the results of an analysis carried out by International Data Corporation IDC's "Analyze the Future". According to the study published in the source [3], mobile phone sales worldwide reached 342 million during the second quarter of 2018. In addition to calling, mobile phones are also widely used for various multimedia activities, such as playing games, chatting, using social networks, etc. This has a serious impact on the attention of their users and can lead to origination of dangerous situations while walking. Several observations have confirmed that pedestrians who type text messages on their phones while walking pay low attention to their surroundings and usually do not perceive trajectory of other people. This can lead to collisions or near collisions. The emergence of such situations is particularly dangerous when crossing a road, as there is another risk factor present-a collision with a motor vehicle. In addition to reduced attention, the risk increases as a result of the isolation of the pedestrian from the sounds in the environment through the use of headphones. This can be extremely dangerous, for example, in the case of an ambulance or a fire truck with alarm siren sound approaching a pedestrian crossing at high speed [4].

The importance of processing the topic of the use of mobile devices and headphones on pedestrian crossings also lies in the fact that this issue is much less explored in comparison to mobile use while driving. Recent years have seen discussions on this issue, especially in foreign countries. The Slovak Republic, however, has not been giving enough attention to these problematics. This is also confirmed by the fact that this issue is not mentioned in the National Road Safety Plan for the Slovak Republic from 2011 to 2020. In order to adopt the Vision Zero Commitment to reduce the number of people killed on the roads, relevant measures need to be taken in each risk area.

The aim of the article is to draw attention to the importance of this topic. The paper presents the basic outputs of the pilot field research on the safety of pedestrians as vulnerable road users, with a focus on the use of mobile devices and headphones at selected non-signalized pedestrian crossings in three Slovak cities. A safety assessment was also carried out at these pedestrian crossings. The importance of assessing the correct construction of pedestrian crossings lies in the fact that in the case of risky behavior of pedestrians, incorrectly constructed pedestrian crossings increase the risk of an accident. The basis for conducting this assessment was a methodology created by the Gdansk University of Technology, which was previously applied to undertake a very complex safety assessment of pedestrian crossings in the city of Warsaw (more information can be found in source [5]).

\subsection{Pedestrian Accidents at the European Level}

In 2018 , a total of about 25,100 people were killed in road accidents across the EU. That means there are 49 deaths per 1 million inhabitants, which is the lowest value in the world. In comparison with 2010, mortality reduction is at $21 \%$, but in comparison to 2017 , there has been a decrease of $1 \%$. It is therefore not very likely that 2020 will achieve the goal of halving the number of traffic casualties compared to 2010. In 2017, 25,300 people lost their lives on European roads. Pedestrians accounted for $21 \%$ of this number, representing 5313 people. In comparison to other road users, the decrease in 
mortality of vulnerable road users was about $5 \%$ lower during the period 2010-2017. It is alarming that pedestrians accounted for $40 \%$ of all people who were killed in a city car accident in 2017. Table 1 shows the number of pedestrians killed in selected EU countries during the period 2007-2017 [6-8].

Table 1. Evolution of the number of pedestrian fatalities in selected EU countries during the period 2007-2017.

\begin{tabular}{cccccccccccc}
\hline & $\mathbf{2 0 0 7}$ & $\mathbf{2 0 0 8}$ & $\mathbf{2 0 0 9}$ & $\mathbf{2 0 1 0}$ & $\mathbf{2 0 1 1}$ & $\mathbf{2 0 1 2}$ & $\mathbf{2 0 1 3}$ & $\mathbf{2 0 1 4}$ & $\mathbf{2 0 1 5}$ & $\mathbf{2 0 1 6}$ & $\mathbf{2 0 1 7}$ \\
\hline Czech Rep. & 232 & 238 & 176 & 168 & 176 & 163 & 162 & 130 & 150 & 130 & 129 \\
Austria & 108 & 102 & 101 & 98 & 87 & 81 & 82 & 71 & 84 & 73 & 73 \\
Hungary & 288 & 251 & 186 & 192 & 124 & 156 & 147 & 152 & 149 & 152 & 170 \\
Poland & 1951 & 1882 & 1467 & 1236 & 1408 & 1157 & 1140 & 1116 & 915 & 868 & 861 \\
Germany & 695 & 653 & 591 & 476 & 614 & 527 & 561 & 527 & 545 & 500 & 489 \\
Great Britain & 663 & 591 & 524 & 415 & 466 & 429 & 405 & 464 & 427 & 463 & - \\
France & 561 & 548 & 496 & 485 & 519 & 489 & 465 & 499 & 466 & 553 & 480 \\
Sweden & 58 & 45 & 44 & 31 & 53 & 50 & 42 & 52 & 28 & 42 & 37 \\
Finland & 48 & 53 & 30 & 35 & 41 & 29 & 34 & 36 & 32 & 29 & - \\
Denmark & 68 & 58 & 52 & 44 & 33 & 31 & 33 & 22 & 27 & 36 & 20 \\
Italy & 627 & 646 & 667 & 621 & 589 & 576 & 551 & 578 & 602 & 570 & 600 \\
Slovakia & 217 & 204 & 113 & 126 & - & - & - & - & - & - & - \\
EU & 8342 & 7865 & 6828 & 6140 & 6232 & 5647 & 5503 & 5506 & 5265 & 5320 & 5313 \\
\% change & - & -5.7 & -13.2 & -10.1 & 1.5 & -9.4 & -2.6 & 0.0 & -4.4 & 1.0 & 0.0 \\
\hline
\end{tabular}

Table is based on EU statistics from sources [6-9]. The 2017 data for Poland are taken from Polish police statistics [10].

\subsection{Pedestrian Accidents in the Slovak Republic}

The Presidium of the Police Forces of the Slovak Republic evaluated the traffic safety situation in Slovakia in 2019. A total of 245 people lost their lives on the roads this year, which is 16 more than in 2018. During this year, 75 pedestrians died on the roads, representing $31 \%$ of all road accident fatalities. Vulnerable road users together make up $45 \%$ of all deaths that occurred on Slovakian roads.

The development of the number of pedestrian accidents in the Slovak Republic is shown in Figure 1. The graph shows that in 2008 a total of 184 pedestrians died on Slovak roads, while in 2019 it was 75 pedestrians. What is alarming, however, is the increase in the number of pedestrians killed since 2017. The presented value is at the same level as the value 8 years ago. A similar development can be observed for the number of pedestrians killed at pedestrian crossings. Since 2016, the number of pedestrian death in these statistics has been increasing every year and the current value is at the level of 2015 or even 2009. Due to the upward trend in these statistics, it is necessary to focus on reducing risk factors that lead to high pedestrian mortality. One of these factors is the use of mobile devices and headphones at pedestrian crossings.

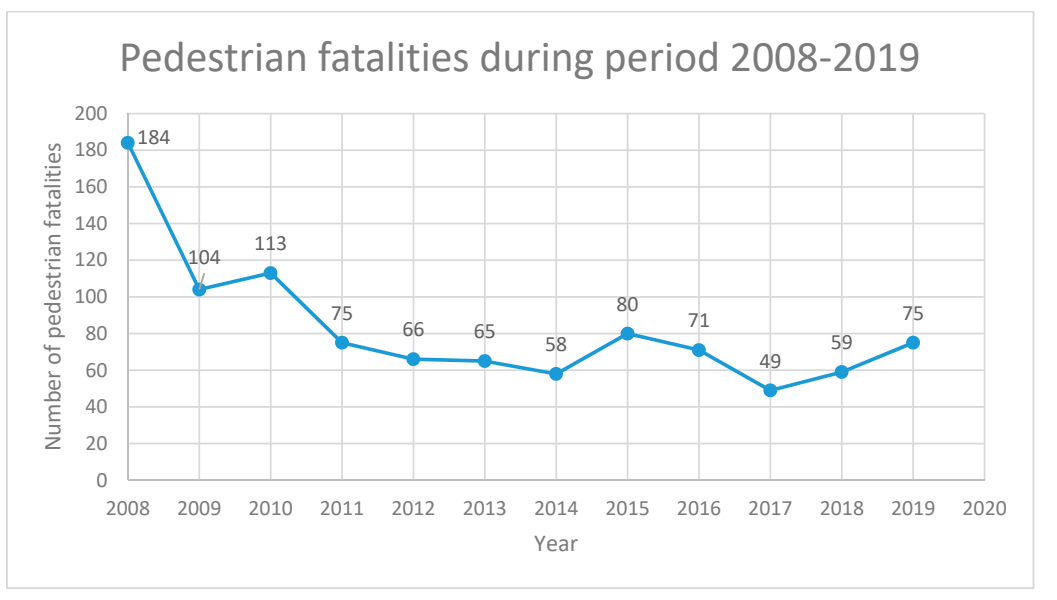

Figure 1. Evolution of pedestrian fatalities in the Slovak Republic during the period 2008-2019. 


\section{Literature Review}

In the following text, the main findings from the literature are presented that are related to the safety of pedestrians in relation to the use of mobile phones and headphones.

\section{Pedestrian Use of Mobile Phones and Headphones}

The importance of the issue of using mobile phones and headphones by pedestrians is confirmed by the number of available articles and documents that indicate the presence of this problem. The use of mobile phones and headphones is mentioned as an important cause of pedestrian accidents for example in the document Pedestrian safety [11]. Several studies point out that, in contrast to the use of mobile phones while driving, for which a number of studies have already been carried out, little attention is paid to pedestrians who use their mobile phones, e.g., for listening to music when crossing the street.

The first research about the problematics started in the USA in 2005. With time, more and more authors are focusing on this issue. In 2019, Greeks Perra Vasilik Maria and Basbas Socrates summarized the theoretical knowledge about this topic on the basis of articles and reports from three scientific databases [12]. The main conclusions are the following: Use of mobile phones or headphones by pedestrians similarly as in the case of drivers of vehicles leads to four types of distractions. It is a cognitive distraction - the pedestrian does not pay enough attention to the correct evaluation of the current situation because they are focusing on the activity they are performing on the mobile phone; a visual distraction-rather than watch the current traffic situation, the pedestrian looks at their mobile device leading to so-called "blindness of attention"; an auditory distraction-the pedestrian does not detect and evaluate the surrounding sound stimuli (e.g., approaching vehicle) due to the use of headphones; a physical distraction-it arises because the pedestrian is focused on other manual activities than just walking.

The issue of the use of mobile phones and headphones for pedestrians has been examined from different perspectives in several sources. The results of these studies lead to the following conclusions: Traffic accidents of pedestrians using a mobile phone most often occur in the age category of persons under 31 years [13]. Texting and using the internet while crossing the road are most common activities for pedestrians in age category 18-30 [14]. The use of mobile phones to listen to music is most common among pedestrians aged 18-44 [15,16]. From a gender perspective, young men are more likely to use mobile phones while walking than young women [17]. Researchers reported in sources [18-20] has led to the conclusion that the use of mobile phones by pedestrians causes that they are walking slower, and their reacting time increases $[17,21]$.

The use of mobile phones can also lead to unusual behavior and strange reactions of pedestrians directly at pedestrian crossings. In the source [22], the authors state that pedestrians entered the pedestrian crossing despite approaching vehicle and stopped directly in front of it at the time when the vehicle also stopped. Research presented at the source [17] has found that pedestrians using mobile phones at pedestrian crossings often enter the crossing too late or are approaching it slowly or sneaking.

Interesting results were presented in studies aimed at comparing the degree of risk that arises for pedestrians when dispersed by individual activities during crossing the road. Sources [23] and [24] have concluded that the safety risk is lower for pedestrians who use a mobile phone than for pedestrians who listen to music through headphones but do not use a mobile device at all when crossing the road. The findings presented in sources [25] and [26] led to the conclusion that there is a higher safety risk for pedestrians who write test messages when crossing the road compared to pedestrians who make phone calls or listen to music through headphones. The results of the research presented in source [27] confirm that the use of personal music equipment is not directly related to the increase in safety risk in pedestrians. Reading text messages is also dangerous, as it leads to distraction and momentary ignorance of events in the environment. [28]. From these conclusions it is clear that the way a mobile phone is used has a direct impact on the degree of safety risk of pedestrian. 
Several quite extensive studies have been conducted about the use of mobile phones and other electronic devices by pedestrians on pedestrian crossings in towns in different countries (e.g., Seattle-USA, Hobart, Queensland-Australia, Lincoln-United Kingdom). To describe the main findings, we selected two: field studies from the cities of Wuhan (China) and Sydney (Australia).

In the city of Wuhan, the topic was studied in 2016. In the city, three pedestrian crossings were selected at intersections that are not controlled by traffic lights. Four cameras were installed at each crossing for video recording of the traffic situation at the intersection. Data were recorded for one day from 7:00 to 9:00 in the morning and from 16:00 to 18:00 in the afternoon. Based on the recorded videos, the following information was evaluated: 1. Gender of pedestrians; 2 . Age of pedestrians-pedestrians were roughly divided into three age groups: pedestrians under the age of 30, middle-aged pedestrians from 30 to 60, seniors over 60 years old; 3 . Time of crossing the road and the speed of crossing; 4. Number of times pedestrians looked around to see if they can walk safely across the road; 5. Mode of mobile phone use-pedestrians were divided into four groups: pedestrians not using a mobile phone, pedestrians looking at the mobile phone display, pedestrians calling and pedestrians listening to music on their headphones.

An evaluation of the video recordings showed that a total of 1241 pedestrians used the pedestrian crossings at the time of the recording. Of this number, 1052 pedestrians $(84.8 \%)$ did not use mobile phones and 189 pedestrians $(15.2 \%)$ used a mobile phone in a certain way when crossing the road, from which 39 pedestrians $(3.1 \%)$ were making a call, up to 138 pedestrians (11.1\%) were looking at the mobile screen and 12 pedestrians (1\%) were listening to music. Table 2 shows mobile use statistics for this city from a variety of observed perspectives.

Table 2. Results of video recording of pedestrian use of mobile devices and headphones on pedestrian crossings in Wuhan, China.

\begin{tabular}{ccccccc}
\hline \multirow{2}{*}{ Way of Using MB } & \multicolumn{3}{c}{ Gender } & \multicolumn{3}{c}{ Age } \\
\cline { 2 - 7 } & & Men & Women & $\mathbf{0 - 3 0}$ & $\mathbf{3 0 - 6 0}$ & $\mathbf{6 0}$ and More \\
\hline \multirow{2}{*}{ Not using MB } & $\mathrm{n}$ & 530 & 522 & 560 & 473 & 19 \\
& $\%$ & 50.4 & 49.6 & 53.2 & 45 & 1.8 \\
\hline \multirow{2}{*}{ Telephoning } & $\mathrm{n}$ & 21 & 18 & 16 & 23 & 0 \\
& $\%$ & 53.8 & 46.2 & 41 & 59 & 0 \\
\hline \multirow{2}{*}{ Looking at the display } & $\mathrm{n}$ & 73 & 65 & 96 & 42 & 0 \\
& $\%$ & 52.9 & 47.1 & 69.6 & 30.4 & 0 \\
\hline \multirow{2}{*}{ Listening to music } & $\mathrm{n}$ & 6 & 6 & 9 & 3 & 0 \\
& $\%$ & 50 & 50 & 75 & 25 & 0 \\
\hline
\end{tabular}

Data are taken from the field research presented in the source [28] (MB-mobile phone).

Data from Table 2 show that mobile phones were used on pedestrian crossings more by men than women, in the case of listening to music the ratio is balanced. Comparing the age structure of pedestrians, it can be stated that young pedestrians listened to music and watched mobile screens more often than adults. The ratio for making phone calls is just the reverse. Chinese seniors did not use mobile devices at all during the recording.

Given the fact that pedestrian behavior was recorded by the cameras, it was possible to derive other interesting statistics, for example, the effect of mobile phone use on pedestrian speed when crossing the road or the number of pedestrian checking-views on the surrounding traffic. As can be seen from Table 3, pedestrians who crossed the road while looking at the mobile phone screen reached a crossing speed $0.7 \mathrm{~m} / \mathrm{s}$ slower than the speed of pedestrians who did not use mobile phones. That means that, if we consider an average passage length of $7 \mathrm{~m}$, the time of crossing the road by pedestrians that use mobile devices is approximately $0.4 \mathrm{~s}$ longer than in the case of pedestrians who do not use mobile devices. From the table it is also evident that pedestrians who are distracted by using 
mobile phones are more inattentive when crossing the road and make fewer glimpses to check the surrounding traffic [29].

Table 3. Influence of mobile phone (MB) and headphone use on pedestrian behavior.

\begin{tabular}{ccc}
\hline Way of Using MB & Pedestrian Crossing Speed (m/s) & Number of Pedestrians \\
\hline Not using MB & 1.18 & 2.236 \\
\hline Telephoning & 1.14 & 1.589 \\
\hline Looking at the MB display & 1.11 & 1.813 \\
\hline Listening to music & 1.12 & 1.791 \\
\hline Data taken from the field research presented in the source [29] (MB-mobile phone).
\end{tabular}

An important survey, related to pedestrian safety, was conducted by NRMA (National Road and Motorists Association) in Sydney. The research was carried out in April and May 2019 at four intersections controlled by traffic lights. It lasted $36 \mathrm{~h}$ and 26,390 pedestrians were observed. Of this number, up to 9494 people (36\%) used mobile phones or headphones on the pedestrian crossings. As the observation was carried out at intersections with traffic lights, the method of crossing the road was also evaluated. In total, up to 2872 pedestrians $(10.9 \%)$ crossed the road in violation of traffic rules, of which 1976 were not using electronic devices, with 896 using them. This means that every hour an average of almost 80 pedestrians crossed the road violating the law in some way (e.g., at a "Stop" signal). If we focus on pedestrian use of electronic devices, every hour on average almost 25 pedestrians crossed the road distracted by this activity and, in addition, violated the traffic rules. The results of the study also showed that violations of the law when crossing the road are more often in the afternoon (the ratio between morning and afternoon hours is from $15 \%$ to $8 \%$ ). With the high intensity of traffic in cities such as Sydney, these are alarming numbers. [30]

The research involved video recording of the area of the three selected pedestrian crossings with traffic lights and was conducted in 2018 in Poland [4]. The results indicate that of the entire population almost $5 \%$ of pedestrians wear headphones. Regarding mobile phone usage, this percentage fluctuated around $10 \%$ of all people using the analyzed pedestrian crossings. It was also found that pedestrians use mobile phones much more often on pedestrian crossings with traffic lights than on pedestrian crossings without traffic lights.

Findings from the presented studies provided the motivation for conducting similar research in Slovakia. In 2019, a pilot study was conducted on this topic in three major cities. The data obtained from this research are presented below.

\section{Materials and Methods}

A pilot study on mobile phone use was conducted at six pedestrian crossings in three different cities during the period from October to December 2019. In total, the research was conducted for $81 \mathrm{~h}$, of which $45 \mathrm{~h}$ were on weekdays and $36 \mathrm{~h}$ on weekends. The study was conducted in three Slovak cities: Žilina, Bratislava and Ružomberok.

The individual crossings were chosen to reflect different age categories of pedestrians. All of the crossings are also characterized by high traffic volumes. Each month, four hours of survey were conducted at particular crossings. Two hours of survey (one hour in the morning and one hour in the afternoon) were performed on weekdays, and two hours at the weekends (also one hour in the morning and one hour in the afternoon). Thus, a total of $12 \mathrm{~h}$ of survey were conducted at each crossing for three months, a total of $36 \mathrm{~h}$ at three crossings in the city of Žilina and $24 \mathrm{~h}$ at two crossings in Ružomberok.

In Bratislava, due to the possibilities of observers, the survey was carried out using a different methodology than in the other two cities. Seven hours of survey were conducted each month to cover each day of the week. On weekdays, the survey was conducted from 
06:50 to $07: 50$, and at the weekends from 10:00 to 11:00. The total number of survey hours in this city was 21.

The survey was conducted by recording data in a census sheet, where pedestrians were grouped according to their estimated age. The weather and visibility conditions were also recorded.

Subsequently, pedestrians were divided into groups according to whether they used mobile devices and headphones when crossing the street:

- $\quad$ Not using mobile phones;

- Using headphones (earpiece in at least one ear);

- Headphones and mobile (typing text or looking at the mobile display);

- Telephoning (including speakerphone);

- Phone check-quick use of the mobile phone on the pedestrian crossing.

The study also included a safety assessment aimed at evaluating the design and quality of the technical conditions at the examined pedestrian crossings. The assessment was performed on the basis of a methodology developed by the Gdansk University of Technology for assessing risks to pedestrian safety [31]. The safety assessment of pedestrian crossings included five areas:

1. Crossing equipment-assessment in terms of equipment for people with disabilities and people with reduced mobility (e.g., reduction in the pavement surface, equipment for visually impaired pedestrians).

2. Visibility of pedestrian crossing from the perspective of drivers - evaluation of the correct design of crossings, parking distance from the crossing and the position of the vehicle parking (e.g., on the road, in a roadside lane, etc.), location and distance of public transport stops, presence of buildings, trees, poles and other obstacles that are disrupting the visibility of pedestrians by drivers. Visibility was measured in real conditions.

3. Traffic signs - the presence of road signs (vertical and horizontal) related to pedestrian crossing markings. Speed limits, condition, type, completeness and the quality of its construction and the correct location were also assessed.

4. Crossing geometry-assessment of the crossing in terms of how it protects pedestrians waiting on the side of the road, presence and width of pedestrian refuge islands, length of pedestrian crossing.

5. Other conditions at the crossing — aspects such as limiting the speed of oncoming vehicles, quality of the pedestrian crossing surface (e.g., presence of rainwater inlets in the area of the crossing, curbside gutters, condition of crossing markings) and the quality of the pavement before the crossing, etc., were evaluated.

By combining the results of observation of pedestrian behavior at concreate pedestrian crossings with findings of safety assessments at these crossings, we can conclude that the safety level of a crossing is not important to pedestrians. Their behavior related to the use of mobile phones and headphones is not influenced by factors such as the visibility of a pedestrian crossing from the perspective of drivers. This is quite alarming because visibility is undoubtedly a crucial factor that influences crossing safety. More information about this finding is provided at the end of fourth chapter.

The results of this assessment are elaborated in detail in a separate piece of work [32] and will not be discussed at length in this paper.

\section{Results}

In this chapter, we present the most important overall results of the research and the survey results in individual cities.

\subsection{Overall Survey Results}

The total number of people observed was 20,285 pedestrians. The graph in Figure 2 shows the summary results of the field research. 


\section{Overall results}

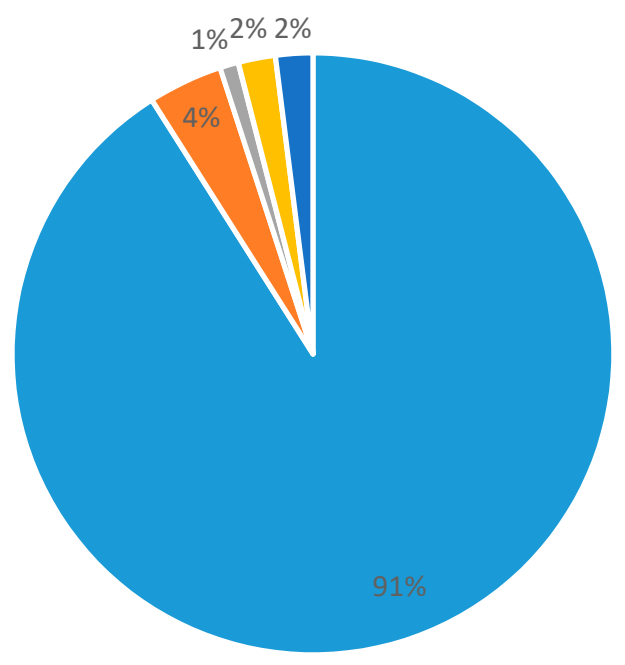

- Not Using Mobiles

- Headphones only

- Headphones + Mobile

- Telephoning

- Phone Check

Figure 2. Total distribution of the use of mobile devices and headphones by pedestrians at observed pedestrian crossings in three Slovak cities.

From the total number of pedestrians observed $(20,285), 91 \%$ did not use the mobile phone at all at pedestrian crossings, $9 \%$ of pedestrians used headphones or mobile devices, which in absolute terms represents 1903 pedestrians, 4\% used headphones, $1 \%$ used headphones and their mobile phone at the same time, $2 \%$ of pedestrians made phone calls and $2 \%$ of pedestrians also used the mobile phone at pedestrian crossings. On average, 23 pedestrians used headphones and mobile phones for each hour of the survey.

However, the survey shows a difference between weekdays and weekends. On weekdays, 13,433 pedestrians used the pedestrian crossings in $45 \mathrm{~h}$ of research. Of this number, 1373 of pedestrians used headphones or mobile phones, which represents $10.2 \%$ of all pedestrians. The result after recalculation to one hour of research during a weekday is interesting. Every hour, an average of 30 pedestrians used their mobile phones or headphones on pedestrian crossings, so every 2 min there was a person at the crossing whose attention was not fully focused on crossing the road safely. These numbers decreased at the weekends. A total of 6852 people used observed crossings on Saturdays and Sundays during $36 \mathrm{~h}$ of our research, of which 530 used headphones and mobile phones $(7.7 \%$ of all observed pedestrians). On average, 14 people used headphones or a mobile phone on pedestrian crossings every hour.

The graph presented in Figure 3 shows the age structure of pedestrians using mobile devices and headphones. The majority are adults, followed by adolescents. A small part consists of children and the smallest percentage is made up of seniors. Parents who used a pedestrian crossing together with their young children are included in the group of adults. In Bratislava and Ružomberok, the majority of pedestrians who were using mobile phones and headphones were adults while in Žilina the devices were most commonly used by adolescent pedestrians. This statistic may be influenced by different estimates of pedestrian age, as the survey was conducted by multiple observers. The result can be also influenced by the location of specific pedestrian crossings, since, e.g., there are more adolescents near schools compared to other parts of the city. 


\section{Age structure of pedestrians using mobiles}

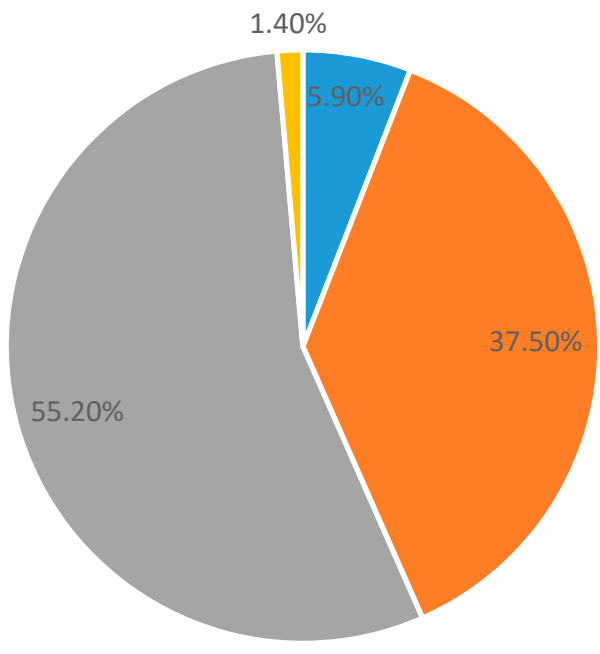

- Children

- Adolescents

- Adults

- Seniors

Figure 3. Distribution of the age structure among pedestrians using mobile devices and headphones at observed pedestrian crossings.

From the total number of 20,285 pedestrians, 55\% were women and $45 \%$ were men. Figure 4 shows the distribution of headphone and mobile phone use by pedestrian gender. Of the total number of 902 pedestrians who used headphones at the crossings, 508 (56.32\%) were men and $394(43.68 \%)$ were women. In the other categories, however, women predominated, with the biggest difference being for pedestrians who were making phone calls. Of the total number of 446 pedestrians who were telephoning, $289(64.8 \%)$ were women, compared to 157 (35.2\%) men.

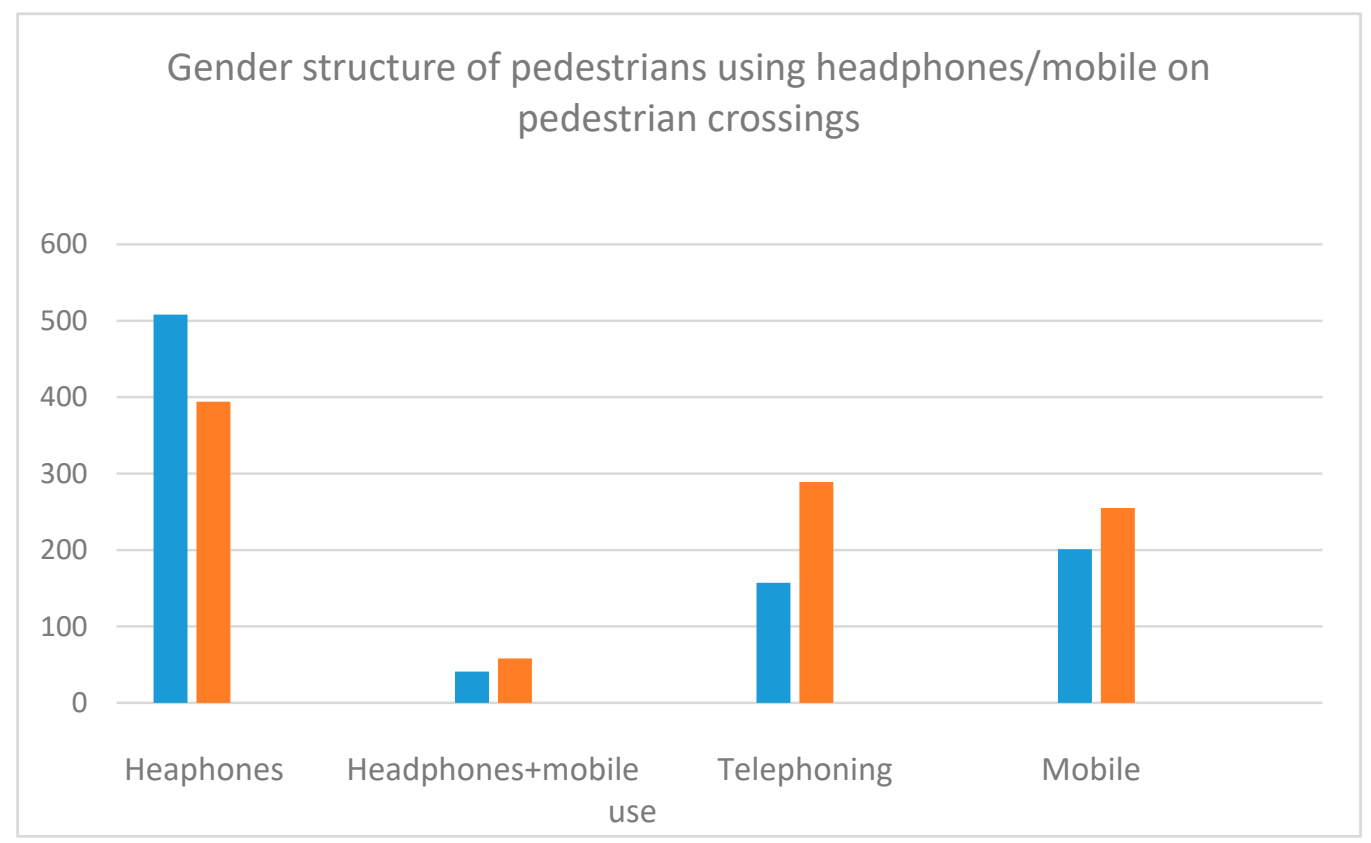

Figure 4. Distribution of the use of mobile devices and headphones by gender among pedestrians at observed pedestrian crossings (blue-men, red-women). 


\subsection{Survey Results in Individual Cities}

Research results in individual cities can be summarized as follows:

\section{- Bratislava}

In the capital of Slovakia, a total of 7497 pedestrians crossed the pedestrian crossing during the survey. Of this number, $6593(87.9 \%)$ did not use mobile phones or headphones and 904 pedestrians $(12.1 \%)$ used these devices. The difference between a working day and a weekend was identified as follows: during weekdays, an average of 44 people used a mobile phone or headphones at pedestrian crossings from the total number that used the crossing every hour, and on weekends this number dropped to 40 pedestrians. Of the 904 pedestrians using the devices, more than half used headphones and about a quarter used a mobile phone while crossing the road, $14 \%$ made phone calls and $5 \%$ used a mobile phone and headphones at the same time. When comparing the gender aspect, the result is very similar to the overall statistics. The headphones were used more by men than women (specifically 257 men and 239 women), in other categories women dominated, while a significant difference is recorded mainly in the category phone calls, where up to 91 women performed this activity while crossing the road, compared to $35 \mathrm{men}$. Regarding the age, $69 \%$ of all pedestrians who used mobile phones or headphones were adults, and this age group predominated in all categories of device use.

- Žilina

In comparison to Bratislava in the other two cities that were included in this research, pedestrians have used mobile phones and headphones to a much lower extent. In the city of Žilina, a total of 7523 people were observed at pedestrian crossings. Of these, 675 of them $(8 \%)$ used electronic devices while crossing the road. The difference between a weekday and the weekend was even more pronounced than in Bratislava. On weekdays, almost 27 pedestrians used mobile phones or headphones at crossings in an average of one hour, and on average only 10 people demonstrated this behavior on weekends. Of the 675 pedestrians who used electronic devices, less than half used headphones. In contrast to the capital, a group of telephoning pedestrians observed in Žilina was in second place (31\%), less than a fifth used a mobile phone and $4 \%$ used mobile phones and headphones at the same time. Regarding the gender distribution, men dominated in the category of headphones (ratio of 195:121), women again made significantly more phone calls (ratio 133:77) and the other two categories were approximately balanced. The use of equipment was prevalent in young people at all three observed crossings in Žilina, which is a significant difference compared to the capital of Slovakia, where mobile phones and headphones were used mainly by adult pedestrians. One of the crossings was mainly used by a group of teenagers and children as it is located close to a primary and secondary school. In total, $28 \%$ of young people and $9 \%$ of children used mobile phones and headphones at this crossing. Young pedestrians in Žilina used headphones the most, reaching in this category significantly higher numbers compared to other age categories. Conversely, adults dominated in telephoning in an equally significant proportion.

When we compare individual pedestrian crossings in Žilina, we find that $10.1 \%$ of pedestrians used equipment at the crossing close to the university, $9.7 \%$ of pedestrians on the crossing that is close to primary and secondary schools and $6.6 \%$ of pedestrians at the crossing located in front of the railway station. However, these relative expressions are influenced by the total number of pedestrians who used the crossing. After recalculating these numbers to one hour of survey, the highest risk pedestrian crossing was at the railway station, where a collision occurred during the survey. A pedestrian looking at their cell phone display stepped onto the road and forced a car driver to brake abruptly.

\section{- Ružomberok}

A total of 4590 people used the observed pedestrian crossings in Ružomberok. Of this number, 324 pedestrians used the devices when crossing the road, which represents $7.1 \%$ of the people. Similarly, to other cities, there was a difference in the use of facilities between 
working days and weekends: on average, almost 19 pedestrians used mobile phones or headphones every hour on weekdays, compared to eight pedestrians on weekends. In this town, telephoning dominated among pedestrians who accounted for $34 \%$ of all people using mobile devices, followed by pedestrians using the mobile phone (30\%). The third most numerous group was pedestrians who used headphones $(28 \%)$, which is a difference compared to the results from the previously mentioned cities. Even in Ružomberok, the least pedestrians (8\%) used mobile phones simultaneously with headphones. Just as in Bratislava, men used headphones more frequently here as well, women dominated in other categories, similarly to the overall results of the survey (the largest predominance in this category was recorded in making telephone calls). In Ružomberok, adult pedestrians used the equipment most often and made up more than half of the people using the equipment. A high percentage (almost $40 \%$ ) is represented by adolescents, the age category of children and seniors makes up a negligible part. Adolescents mostly used headphones, while adults made up the vast majority of pedestrians making phone calls and using mobile phones when crossing the road.

\subsection{Influence of Traffic Intensity and Visibility Level of Pedestrian Crossing on Pedestrians' Behavior}

An interesting finding was observed when comparing traffic intensity and pedestrians' behavior. Figure 5 describes correlation between the traffic intensity (volume of vehicles that passed observed pedestrian crossings) and the percentage of pedestrians who used a mobile phone and/or headphones (from all the persons observed at pedestrian crossings) during the implementation of the present study.

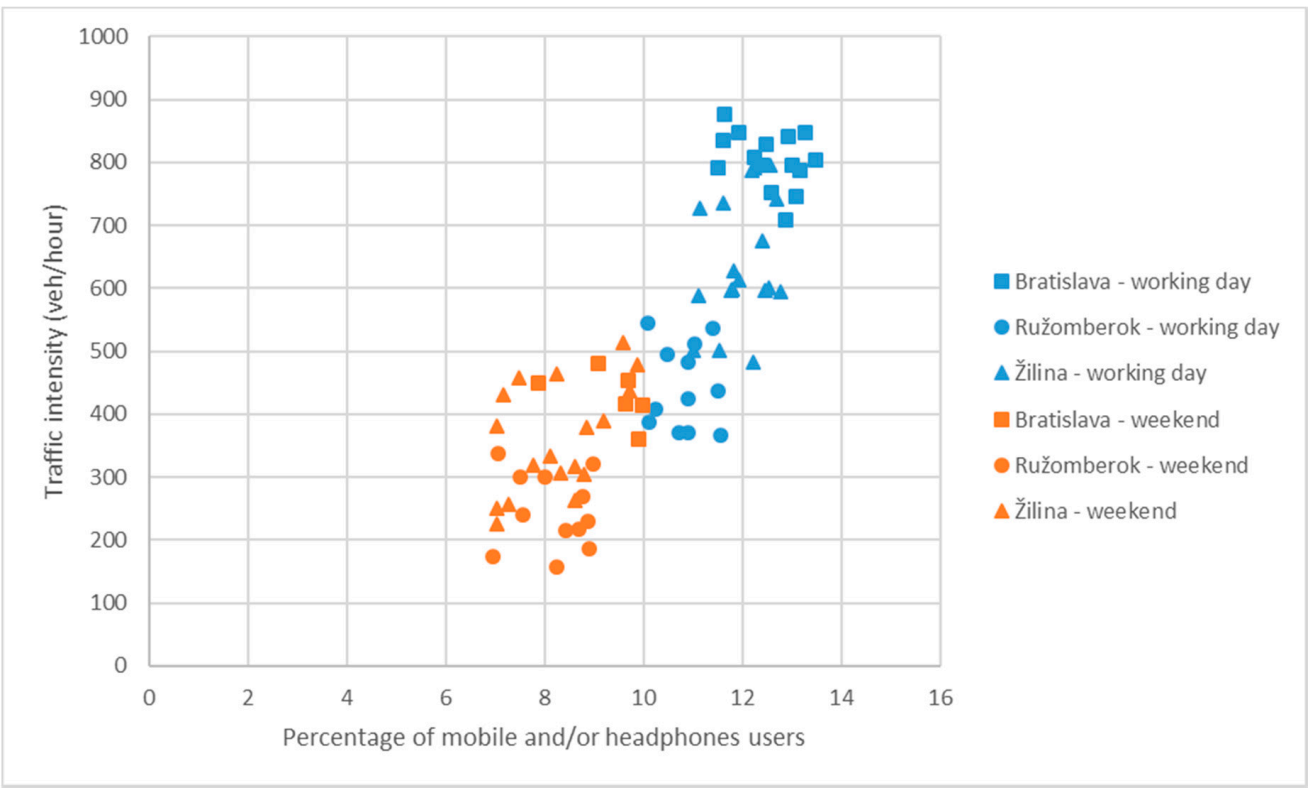

Figure 5. Relation between traffic intensity and percentage of pedestrians using mobile phone/headphones at observed pedestrian crossings.

According to these results, the volume of traffic does not affect the behavior of pedestrians. There was no trend identified in the percentage of mobile phone/headphones users with increased traffic. In several cases, the figure even shows that the percentage of pedestrians using mobile phones/headphones increased with higher traffic volumes.

Different signs were used to demonstrate the situation observed in individual cities (Bratislava-square sign, Ružomberok—round sign and Žilina—triangular sign). On average, $12.06 \%$ of pedestrians used mobile phones/headphones in Bratislava, $8.97 \%$ of pedestrians used phones/headphones in Žilina and $7.05 \%$ of pedestrians used phones/headphones in Ružomberok. These numbers seem to increase with the size of the city (in terms of 
territory and population). This trend is confirmed also by the studies carried out abroad that were mentioned in previous part of paper (e.g., Sydney and the City of Wuhan).

As different behaviors were observed during working days and weekends, the data were also divided according to this criterion (blue color-working days, red colorweekends). According to observations made on working days: on average, $8.8 \%$ of pedestrians used mobile phones/headphones in Bratislava, $6.46 \%$ of pedestrians used mobile phones/headphones in Žilina and $4.97 \%$ of pedestrians used mobile phones/headphones in Ružomberok. According to observations made on weekends: on average, $3.2 \%$ of pedestrians used mobile phones/headphones in Bratislava, 2.39\% of pedestrians used mobile phones/headphones in Žilina and $2.09 \%$ of pedestrians used mobile phones/headphones in Ružomberok. The growing trend, which depends on the size of the city, can also be observed on these desegregated data.

Another interesting finding resulted from combining the results of observation of pedestrian behavior at concrete pedestrian crossings with findings of safety assessments at these crossings. Part of this assessment was the evaluation of an adequate safety solution of a pedestrian crossing in terms of its visibility and the visibility of its users. This procedure was focused mainly on the aspects associated with the geometry of the road and roadside elements. It was evaluated if the visibility was not obscured or restricted by objects or elements such as, for example: parked vehicles, trees, overgrown vegetation or street furniture. In addition, particular visibility problems for children, wheelchair users and other pedestrians with mobility impairments were included into this evaluation. Where relevant, the aspect of pedestrian crossing locations in relation to the distances needed to ensure a safe intersection has also been taken into account. The presence and condition of the horizontal and vertical traffic signs were also taken into consideration, together with additional lighting of pedestrian crossing.

Visibility level of the crossings was evaluated using scale from 1 (lowest) to 6 (highest). The aspects considered for determination of this level were the following ones:

- Presence and condition of the horizontal and vertical traffic signs (visibility, clarity, recognizability and correct position of traffic signs);

- Presence of the objects and elements obstructing visibility in the area of "good visibility" of pedestrian crossing (this area was established using the methodology and formulas provided in source [33]);

- Location of pedestrian crossing in relation to the distances needed to ensure a safe intersection (these distances were established using the formulas provided in source [34]);

- Lightening aspect of pedestrian crossing (it was evaluated on the basis of methodology described in source [35]).

Figure 6 describes the relation between the level of visibility assigned to each pedestrian crossing and the percentage of pedestrians who used mobile phones/headphones during observations on weekdays (diamond sign) and weekends (round sign). Similar results were identified at pedestrian crossings with different visibility levels (e.g., from 10.8 to $12.1 \%$ of mobile/headphones users were observed at pedestrian crossings with visibility levels 3,4 and 5). From the presented results, we can conclude that the level of visibility of individual pedestrian crossing from the driver's point of view does not affect the behavior of pedestrians.

Although the number of measurements was not high enough to be the results statistically significant, they can be considered interesting and can be the basis and motivation for the implementation of a larger study. 


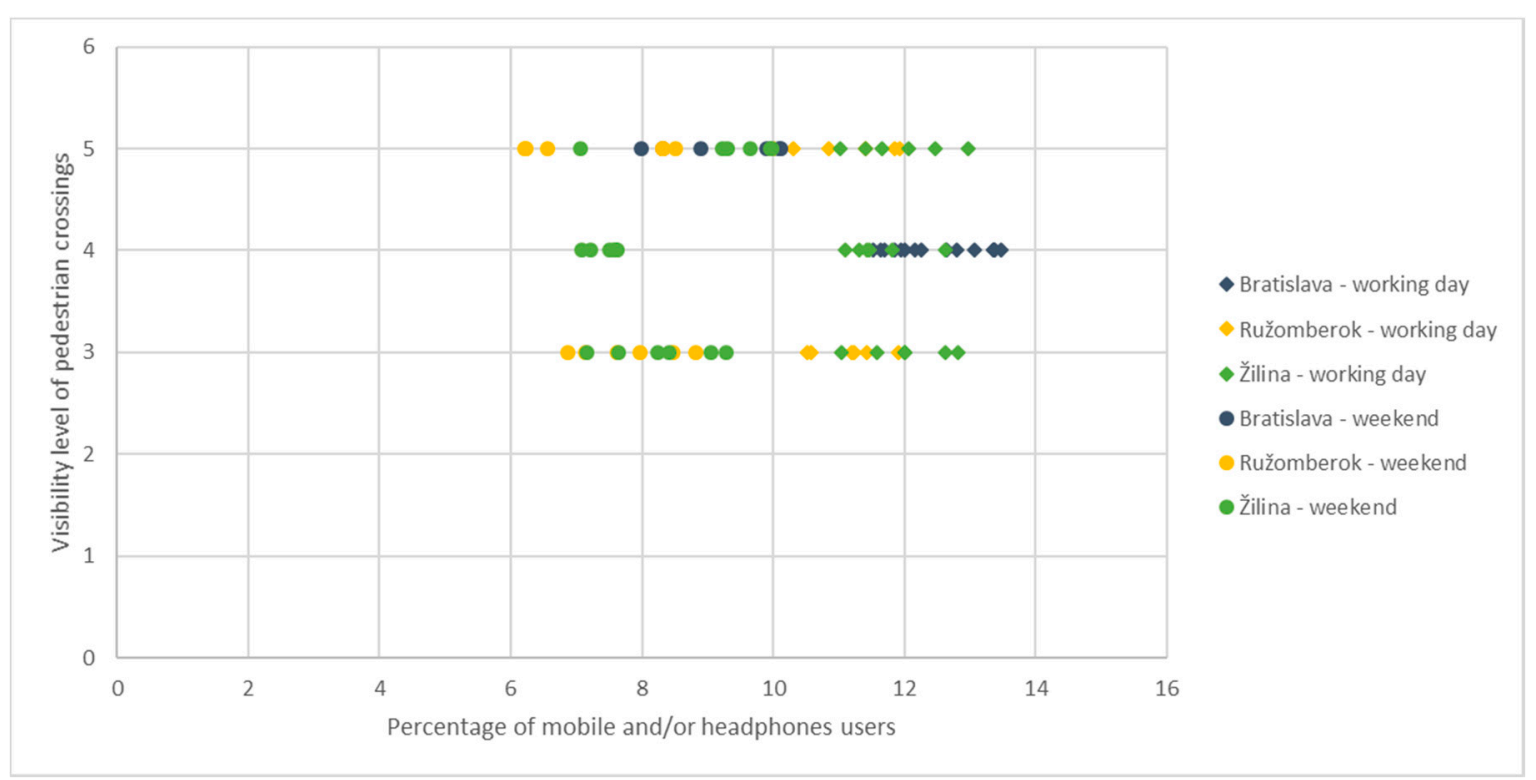

Figure 6. Relation between the visibility level of pedestrian crossings and percentage of pedestrians using mobile phone/headphones at observed pedestrian crossings.

\section{Discussion}

The results of the pilot field research, that were presented in this paper, confirm the importance of paying attention to the problem of using mobile devices and headphones on pedestrian crossings. In the future, we expect an increase in the seriousness of this problem. This is closely linked to the area of legislative bans on the use of phones and handsets by pedestrians when they are crossing the road.

In recent years, this issue has resonated with several countries around the world. In October 2017, a law was adopted in the Hawaiian capital of Honolulu banning pedestrians from using mobile phones and other devices (such as tablets) when crossing the road. An exception is an emergency call to 911. The fine for the first offence is USD 15, for repeated violations pedestrians may be fined USD 75-95. Based on the growing number of injured pedestrians using these devices, the US National Security Council has introduced a special category for this group of road users in its statistical reports in order to monitor developments in this area [36]. A similar law has been adopted in some other smaller US cities.

In May 2019, the same law was proposed in New York City. It included writing messages and emails or surfing the internet. The proposed fines were even higher than in the case of Honolulu: for the first offences the fine was at the level of USD 25-50 and USD 250 for repeated offences. Senator John Liu commented on the subject: "It is difficult not to notice all those people who are tapping on their mobile phones while walking, and it is even worse to watch them as they continue to walk across the road." [37,38]. However, the proposed law also found opponents who argued that the use of mobile devices at pedestrian crossings is not a common cause of injury or death, and the Hawaiian law is not based on any research. According to Honolulu statistics, pedestrian accidents have even doubled since the law was adopted. Subsequently, in August 2019, the Department of Transport in New York City drew up a report which claims that distraction of pedestrians is not among the main factors of pedestrian road accidents. This municipal authority has been dealing with this issue for a long time. In 2017, the city even conducted a study at three signalized intersections, according to which $13 \%$ of pedestrians used the device and $87 \%$ of people crossed the road without the use of mobile phones or other devices. A similar survey was conducted in New York in 2018 by the University of Northern Arizona. According to the results, $9 \%$ of pedestrians were texting on their mobile phones when crossing the road. However, according to statistics for the entire USA, for the period 
2010-2015, only $0.2 \%$ of pedestrians suffered fatal accidents caused by the use of electronic devices, and a minimum of similar cases was recorded in the city. In addition, the New York City Transportation Department is engaged in a variety of educational activities (such as the Cross this Way campaign, which focuses on the dangers of using mobile devices by pedestrians, so they decided to focus on speed [39]. Based on these facts, the law has eventually not been adopted.

The same problems have been addressed on the other side of the globe, in Australia. In this country, in 2018, the Pedestrian Council put forward a proposal to the government to fine pedestrians using electronic devices while crossing the road with fines of up to USD 200. This sanction should also apply if a pedestrian crosses a road at a signalized crossing when the light is green. Certain fines for pedestrians have already been introduced, e.g., a penalty of up to USD 80 has been imposed for crossing the road outside the pedestrian crossing. Harold Scruby, chairman of the Pedestrian Council, argued that the fine for pedestrians for using mobile phones and headphones at the crossings must be high, otherwise it would not force people to be careful when crossing the road. He also added that pedestrians using mobile phones or headphones also endanger other road users by forcing drivers to suddenly change direction [40]. Similar to the United States, Australia did not find support in all countries, but information on a possible law for this group of pedestrians appeared as early as in 2020 .

Within the European Union, in 2018, Lithuania adopted a law banning the use of mobile devices when crossing the road. Fines for non-compliance are lower compared to the above-mentioned states, the upper rate being EUR 40. With this measure, the state responded to the high percentage of pedestrians killed in traffic accidents in the country. In terms of statistics, Lithuania was above the EU average [41].

Discussions regarding the legislative solution to the problem are not new in the Slovak Republic either. Act No 8/2009 in its original proposal contained a prohibition for pedestrians to use mobile phones, electronic devices for listening to music, or other technical devices that are distracting their attention when they are crossing the road [42]. This original proposal was not supported by the deputies and the president vetoed it. This ban no longer appeared in the new law.

From the information presented above, it is clear that the most appropriate solution should be to adopt some kind of regulation at the level of the European Union, which would then be transposed by individual countries into their legislation. This procedure should be a benchmark for other countries around the world.

\section{Conclusions}

The pilot study and applied methodology were inspired by research carried out in the field of the use of electronic devices by pedestrians abroad. This was an excellent basis for the validation of the study methodology and guarantee of study quality.

The importance of this study is based on the fact that it was Slovakia's first field research on this topic. The time scale of the survey and the overall sample of pedestrians observed helped to provide relevant results on the basis of which further investigations or comparisons with other countries can be drawn.

The overall results can be summarized as follows: In total, $9 \%$ of the observed pedestrians used headphones or mobile devices at pedestrian crossings ( $4 \%$ used headphones, $1 \%$ used headphones and at the same time used their mobile phones, $2 \%$ of pedestrians made phone calls and $2 \%$ of pedestrians also used the mobile phone). However, the survey showed an interesting difference between a working day and a weekend. On weekdays, the number was $10.2 \%$ of all pedestrians and $7.7 \%$ on weekends. Regarding the gender distribution, the men were predominant in the use of headphones $(56.32 \%$ of pedestrians were men and $43.68 \%$ were women). In the other categories, however, women predominated, with the biggest difference in the category of pedestrians who were telephoning $(64.8 \%$ were women and $35.2 \%$ were men). 
After recalculating the survey results for one hour, it was established that on average there were 23 pedestrians on the crossing using headphones and mobile phones. On weekdays every hour, an average of 30 pedestrians used their mobile phones or headphones at the crossing. This means that every 2 min there was a person at the crossing whose attention was not fully focused on crossing the road safely. The difference between a working day (30 pedestrians/h) and a weekend (14 pedestrians $/ \mathrm{h}$ ) was quite significant. It is also interesting that in Bratislava on a weekday, on average, up to 44 pedestrians every hour were on the crossings using mobile phones and headphones.

Another interesting finding of this study was that even when the safety risk at pedestrian crossings was heightened due to rush hour traffic and reduced pedestrian visibility (e.g., getting dark or in bad weather), the behavior of pedestrians related to the use of mobile phones and headphones did not change. This trend was observed in all three cities.

Finally, the crossings assessed featured a low level of safety design. It is important to note that if a pedestrian is inattentive because they are using a mobile phone or headphones at a pedestrian crossing which is, in addition, improperly designed from the safety point of view, the risk is doubled, and the probability of an accident is high.

Combining the results of observation of pedestrian behavior at concrete pedestrian crossings with findings of safety assessments at these crossings we can conclude that pedestrians do not consider factors such as good visibility of the pedestrian crossing from the point of view of drivers. That is quite alarming as the visibility is undoubtedly a crucial factor influencing crossing safety.

In relation to the survey results in individual cities, we can conclude that most pedestrians used mobiles and headphones in Bratislava (the biggest city), the smallest part was observed in Ružomberok (the smallest city), with a difference of 5\% between these cities. Based on these results, it can be argued that the problem of pedestrians using electronic devices is more widespread in cities with larger populations. This is also confirmed by the results of surveys from China and Australia, where surveys were conducted in cities such as Wuhan and Sydney, and where pedestrians using electronic devices accounted for $15.2 \%$ and $36 \%$ of all pedestrians, respectively. The survey in Sydney was carried out on signalized pedestrian crossings, which reduces the risk of a pedestrian accident if the traffic rules are followed. However, the results of the survey showed that a large number of pedestrians crossed the road in a way that violated the rules, which means that there is a high probability of an accident also at intersections with traffic lights. A significant number of these pedestrians were pedestrians using mobile devices or headphones, which multiplies the risk of an accident, because the driver of an oncoming vehicle at light-controlled intersections does not expect an obstacle on the road and the attention of a pedestrian breaking the law is distracted.

It is evident that the problem of pedestrians who use electronic devices at pedestrian crossings needs to be properly addressed. This has been confirmed by the number of examples of measures that have been taken abroad. It is interesting that in Slovakia, a bill banning pedestrians using electronic devices when they are crossing the road appeared in 2008. However, it was not approved and since then little attention has been paid to this issue. A large part of the National Road Safety Plan for the Slovak Republic from 2011 to 2020 is dedicated to the measures that should increase the safety of pedestrians, but the issue of the use of electronic devices by pedestrians is not mentioned in this document. In Slovakia, however, we can see a significant increase by more than 50 percent in pedestrian mortality over the last two years. In addition, in view of the effort to meet the international "zero accident vision" by 2050, it is essential that relevant measures are taken to increase pedestrian safety in every single problem area. The impact of the use of electronic devices on pedestrian safety certainly belongs to such problem areas, because according to the results of our research, almost one-tenth of pedestrians that are involved in road traffic accidents are people whose attention is distracted by the use of modern technical equipment. 
It is also important to note that the study was conducted in the autumn and winter suggesting that the detected numbers of pedestrians who were using mobiles and headphones at pedestrian crossings can be lower than otherwise due to the use of warm clothing by pedestrians during these seasons (e.g., in cases when the observer was unable to detect the use of wireless headphones on a pedestrian if the pedestrian wore a cap).

Although the results of this study cannot be considered statistically significant, due to restricted number of measurements performed, they can be considered interesting and can be the basis and motivation for the implementation of a larger study.

From our point of view, there are two issues that we would like to take into account in the future work related to our study. We would like to include the factor of interaction between pedestrian and driver with a focus on the driver speed behavior related to pedestrians (who are already on, or are about to step onto, the pedestrian crossing) and identify critical situations caused by improper behavior of drivers and/or pedestrians. This will help to reveal speed adaptation problems related to pedestrian crossings. For this purpose, the research will be conducted by video recording and applying artificial intelligence (that will be used, e.g., for counting the number of pedestrians and identifying behaviors that are relevant for the observation).

Author Contributions: Conceptualization, M.M. and J.W.; methodology, M.M.; validation, M.M., J.W. and J.Z.; formal analysis, M.M.; investigation, M.M.; resources, J.Z.; data curation, M.M. and J.W.; writing—original draft preparation, M.M.; writing—review and editing, M.M., J.W.; visualization, M.M.; supervision, J.Z.; project administration, M.M.; funding acquisition, M.M. All authors have read and agreed to the published version of the manuscript.

Funding: This research received no external funding.

Institutional Review Board Statement: Not applicable.

Data Availability Statement: Data that support the findings of this study are available from the corresponding author upon reasonable request.

Conflicts of Interest: The authors declare no conflict of interest.

\section{References}

1. European Road Safety Observatory. Pedestrians and Cyclists 2018. P. 7. Available online: https://ec.europa.eu/transport/road_ safety/sites/roadsafety / files/pdf/ersosynthesis2018-pedestrianscyclists.pdf (accessed on 5 April 2020).

2. European Commission: 2019 Road Safety Statistics: What is Behind the Figures? Press Release. 11 June 2020. Brussels. Available online: https:/ / ec.europa.eu/commission/presscorner/detail/en/QANDA_20_1004 (accessed on 5 April 2020).

3. Wirtualnemedia. n.d. Sprzedaż Smartfonów w II Kwartale Zmalała. Liderem Samsung, Huawei Wyprzedził Apple. Available online: https:/ / www.wirtualnemedia.pl/artykul/sprzedaz-smartfonow-w-ii-kwartale-zmalala-liderem-samsung-huaweiwyprzedzil-apple (accessed on 21 May 2020).

4. Wachnicka, J.; Kulesza, K. Does the use of cell phones and headphones at the signalised pedestrian crossings increase the risk of accident? Balt. J. Road Bridg. Eng. 2020, 15, 96-108. [CrossRef]

5. Kustra, W.; Jamroz, K.; Budzynski, M. Safety PL-A Support Tool for Road Safety Impact Assessment. Transp. Res. Procedia 2016, 16, 3456-3465. [CrossRef]

6. European Commission. Fatalities as Reported by Road User Type in EU Countries. pp. 1-55. Available online: https:// ec.europa.eu/transport/road_safety/sites/roadsafety/files/pdf/statistics/historical_country_person_class.pdf (accessed on 2 February 2020).

7. European Commission. 2018 Road Safety Statistics: What is Behind the Figures? Press communication, MEMO/19/1990; European Commission: Brussel, Belgium, 2018; Available online: https://ec.europa.eu/commission/presscorner/detail/en/MEMO_19_1 990 (accessed on 16 June 2020).

8. European Commission. Road Safety in the European Union-Trends, Statistics and Main Challenges; Publications Office of the European Union: Luxemburg, 2018; p. 26. Available online: https:/ / ec.europa.eu/transport/road_safety/sites/roadsafety/files/ vademecum_2018.pdf (accessed on 7 February 2020).

9. European Road Safety Observatory. Traffic Safety Basic Facts 2018: Pedestrians. p. 24. Available online: https:/ / ec.europa.eu/ transport/road_safety/sites/roadsafety/files/pdf/statistics/dacota/bfs20xx_pedestrians.pdf (accessed on 7 February 2020).

10. Symon, E. Wypadki Drogowe w Polsce 2017 Roku; Wydział Opiniodawczo-Analityczny Biura Ruchu Drogowego Komendy Głównej Policji: Warsaw, Poland, 2018; Available online: http://statystyka.policja.pl/st/ruch-drogowy/76562,Wypadki-drogoweraporty-roczne.html (accessed on 26 March 2020). 
11. World Health Organization. Pedestrian Safety: A Road Safety Manual for Decision-Makers and Practitioners; Communication: Geneva, Switzerland, 2013; p. 114. Available online: https://apps.who.int/iris/bitstream/handle/10665/79753/9789241505352_eng.pdf; jsessionid=690FEA977F11D9379EA101583FD3F64B? sequence=1 (accessed on 31 January 2020).

12. Perra, V.M.; Basbas, S. Distracted Walking and the Impact of Mobile Phone use: A Literature Review; Young Researches Seminar: Thessaloniki, Greece, 2019.

13. Nasar, J.L.; Troyer, D. Pedestrian injuries due to mobile phone use in public places. Accid. Anal. Prev. 2013, 57, 91-95. [CrossRef] [PubMed]

14. Lennon, A.; Williamson, A.; King, M.; Lewis, I.; Rose, E. Distraction and Attitudes Towards Safe Pedestrian Behaviour; Austroads Ltd.: Sydney, Australia, 2016.

15. Huk, M. Stochastic Optimization of Contextual Neural Networks with RMSprop. In Proceedings of the 12th Asian Conference on Intelligent Information and Database Systems, ACIIDS 2020, Phuket, Thailand, 23-26 March 2020; 12034, pp. $343-352$.

16. Huk, M. Training contextual neural networks with rectifier activation functions: Role and adoption of sorting methods. J. Intell. Fuzzy Syst. 2019, 38, 1-10. [CrossRef]

17. Zhou, Z.; Liu, S.; Xu, W.; Pu, Z.; Zhang, S.; Zhou, Y. Impacts of mobile phone distractions on pedestrian crossing behavior at signalized intersections: An observational study in China. Adv. Mech. Eng. 2019, 11, 1-8. [CrossRef]

18. Haga, S.; Sano, D.A.; Sekine, Y.; Sato, H.; Yamaguchi, S.; Masuda, K. Effects of using a Smart Phone on Pedestrians' Attention and Walking. Procedia Manuf. 2015, 3, 2574-2580. [CrossRef]

19. Jiang, K.; Ling, F.; Feng, Z.; Ma, C.; Kumfer, W.; Shao, C.; Wang, K. Effects of mobile phone distraction on pedestrians' crossing behavior and visual attention allocation at a signalized intersection: An outdoor experimental study. Accid. Anal. Prev. 2018, 115, 170-177. [CrossRef] [PubMed]

20. Hatfield, J.; Murphy, S. The effects of mobile phone use on pedestrian crossing behaviour at signalised and unsignalised intersections. Accid. Anal. Prev. 2007, 39, 197-205. [CrossRef] [PubMed]

21. Tapiro, H.; Oron-Gilad, T.; Parmet, Y. Cell phone conversations and child pedestrian's crossing behavior: A simulator study. Saf. Sci. 2016, 89, 36-44. [CrossRef]

22. Nasar, Y.; Hecht, P.; Wener, R. Mobile telephones, distracted attention, and pedestrian safety. Accid. Anal. Prev. 2008, 40, 69-75. [CrossRef] [PubMed]

23. Neider, M.B.; McCarley, J.S.; Crowell, J.A.; Kaczmarski, H.; Kramer, A.F. Pedestrians, vehicles, and cell phones. Accid. Anal. Prev. 2010, 42, 589-594. [CrossRef] [PubMed]

24. Stavrinos, D.; Byington, K.W.; Schwebel, D.C. Distracted walking: Cell phones increase injury risk for college pedestrians. J. Safety Res. 2011, 42, 101-107. [CrossRef] [PubMed]

25. Antic, B.; Milenkovic, M.; Glavic, D.; Pešic, D. The effects of mobile phone use on pedestrian crossing behaviour at unsignalized intersections-Models for predicting unsafe pedestrians behaviour. Safety 2016, 82, 1-8. [CrossRef]

26. Schwebel, D.C.; Stavrinos, D.; Byington, K.W.; Davis, T.; O'Neal, E.E.; De Jong, D. Distraction and pedestrian safety: How talking on the phone, texting, and listening to music impact crossing the street. Accid. Anal. Prev. 2015, 45, 266-271. [CrossRef] [PubMed]

27. Walker, E.J.; Lanthier, S.N.; Risko, E.F.; Kingstone, A. The effects of personal music devices on pedestrian behaviour. Saf. Sci. 2012, 50, 123-128. [CrossRef]

28. Lin, M.I.B.; Huang, Y.P. The impact of walking while using a smartphone on pedestrians' awareness of roadside events. Accid. Anal. Prev. 2017, 101, 87-96. [CrossRef] [PubMed]

29. Cunbao, Z. The Effects of Mobile Phone Use on Pedestrian Crossing Behaviour and Safety at Unsignalized Intersections. In Proceedings of the 4th International Conference on Transportation Information and Safety (ICTIS), Banff, AB, Canada, 8-10 August 2017; pp. 280-285. Available online: https://www.researchgate.net/publication/319973466_The_effects_of_mobile_ phone_use_on_pedestrian_crossing_behavior_and_safety_at_unsignalized_intersections (accessed on 29 February 2020).

30. National Road and Motorists Association. Look up: Keeping Pedestrian Safe. 2019. Available online: https://www.mynrma.com. au/- / media/documents/advocacy /look-up-keeping-pedestrians-safe.pdf?la=en\&hash=83AF22A582EF35C901E303FE7B6A2 BFD (accessed on 3 August 2020).

31. Mackun, T.; Rys, A.; Tomczuk, P. Risk assessment methodologies for pedestrian crossings without traffic lights-Warsaw case study-pedestrian safety assessment. In Proceedings of the 11th International Road Safety Seminar GAMBIT 2016, Gdansk, Poland, 17-18 November 2016; MATEC Web Conference. 2017; 122, p. 01004. [CrossRef]

32. Kamenik, P. Assessment of Pedestrian Crossings and Pedestrian Behavior in Selected Cases (in Slovak). Bachelor's Thesis, University of Zilina, Zilina, Slovakia, 24 May 2020.

33. Jamroz, K.; Kempa, J.; Rychlewska, J.; Mackun, T. The Method of Determining the Area of Good Visibility at Pedestrian Crossings in Poland (in polish). Transpot Miejski Iregionalny 2015, 4, 10-21. Available online: https:/ / www.researchgate.net/publication/27 6354370_Metoda_wyznaczania_obszaru_dobrej_widocznosci_na_przejsciach_dla_pieszych_w_Polsce (accessed on 14 October 2020).

34. Basile, O.; Persia, L.; Shingo Usami, D. A methodology to assess pedestrian crossing safety. Eur. Transp. Res. Rev. 2010, 2, 129-137. [CrossRef]

35. Tomczuk, P.; Chrzanowicz, M.; Mackun, T. Methodology for assessing the lighting of pedestrian crossings based on light intensity parameters. In Proceedings of the 11th International Road Safety Seminar GAMBIT 2016, Gdansk, Poland, 17-18 November 2016; MATEC Web Confonference. 2017; 122, p. 01004. [CrossRef] 
36. Chappell, B. Honolulu's 'Distracted Walking' Law Takes Effect, Targeting Phone Users. NPR. Available online: https: / / www.npr.org/sections/thetwo-way/2017/10/25/559980080/honolulus-distracted-walking-law-takes-effect-targetingphone-users? $\mathrm{t}=1581427595368 \& \mathrm{t}=1585640571899$ (accessed on 10 October 2020).

37. Otajovičová, S. New York is Planning to Ban Pedestrians from Using Cell Phones at Crossings (in Slovak). 2019. Available online: https:/ / www.startitup.sk/v-new-yorku-chcu-zakazat-pouzivat-chodcom-na-priechodoch-mobilne-telefony/ (accessed on 10 October 2020).

38. Augusta, A. New York Might Make it Illegal to Text While Walking. 2019. Available online: https://edition.cnn.com/2019/05/20 / us/new-york-walking-while-texting-trnd/index.html?fbclid=IwAR2dbUdfj2Vzms8FYIhiToruRk0gcecOnMNGi1eTBrWR7 B6hzXCCCnIgE-M (accessed on 22 September 2020).

39. A New York City Department of Transportation. Distraction Shouldn't Be Deadly. 2019. Available online: https://nyc.streetsblog. org / 2019/09/02/ city-to-state-distracted-pedestrians-is-not-a-thing/ (accessed on 22 September 2020).

40. Foster, A. Calls for New Fine that Would See Pedestrians Penalised \$200. Available online: https://www.news.com.au/ technology/innovation/motoring/on-the-road/calls-for-new-fine-that-would-see-pedestrians-penalised-200/news-story / 84 058822a7ae95cddf82585c7e26033e (accessed on 10 October 2020).

41. Shakhil, S. Lithuanians Face Fines for Using Phones While Crossing the Street. 4 October 2018. Available online: https: / / emergingeurope.com/news/lithuanians-face-fines-for-using-phones-while-crossing-the-street/ (accessed on 22 September 2020).

42. MV SR. Road Safety Rules Will Change from the 1st of February (in Slovak). Press Release. 21 January 2009. Available online: https:/ / www.minv.sk/?tlacove-spravy\&sprava=od-1-februara-2009-sa-zmenili-pravidla-cestnej-premavky (accessed on 22 September 2020). 